\title{
HERMENÊUTICA E PSICANÁLISE
}

Luiz Carlos Santuário*

SINTESE - Tradicionalmente, filosofia e psicanálise muito pouco dialogam. O trabalho procura ampliar esta área de contato através de um confronto entre a fenomenologia hermenêutica de Heidegger, em relação à análise do Dasein; a hermenêutica gadameriana, e o seu apelo à linguagem como ambiente do humano e, de outro lado, a psicanálise de Lacan. Não se trata de psicanalisar a filosofia mas, sim, tentar aprofundar o debate entre estas duas áreas, para possibilitar a determinação daquilo que é especifico a cada campo.

PALAVRAS-CHAVE - Hermenêutica. Linguagem. Psicanálise.
ABSTRACT - Traditionally, philosophy and psychoanalysis do not dialog very often. This paper aims to widen this contact through a confrontation among Heidegger's hermeneutics of Dasein; Gadamer's hermeneutics, by his appeal of language as human's environment, and, on the other hand, Lacan's psychoanalysis. It is not a question to make psychoanalysis of philosophical concepts but to deepen the debate between these two areas to determine what could be justifiable concerning to which field.

KEY WORDS - Hermeneutics. Language. Psychoanalysis.

\section{Da atividade filosófica}

Aquilo que deve ser compreendido como o "objeto" do discurso ou do saber produzido pela atividade filosófica não se constitui em algo que possa ser abordado pelo caminho diretamente ontológico, ${ }^{1}$ (onde se trata apenas da exposição conceitual de um saber, ou de uma concepção ontológica singular²) como seria a atividade de catalogar e classificar objetos do mundo empírico, como mesas, cadeiras, árvores, etc. Através do emprego do odós diretamente ontológico, produzse, para a consciência, apenas a ingênua ilusão da suposta apreensão direta de objetos.

Ao contrário, o discurso filosófico constitui-se, de modo mais adequado, através do modus indiretamente ontológico, onde tratar-se-ia da atividade de produção de um saber, através de um processo especulativo.

* Professor da Universidade de Caxias do Sul (UCS) e doutorando do Programa de Pós-Graduação em Filosofia da PUCRS.

1 GAUVIN, J. O discurso da filosofia sistemática. Coimbra: Almedina, 1973, p. 178.

2 Idem, op. cit., p. 180.

3 Caminho ou método. 
Acredito poder compreender este processo de produção do saber filosófico através do modus indiretamente ontológico, como um processo de tradução ou de digitalização $o^{4}$ do sentido. Esta operação, ou torção, produzida pelo saber filosófico constitui-se como antípoda ao saber do senso comum, o qual (possivelmente), graças ao imperialismo da mídia, tem uma compreensão acronimáticáa da realidade.

Este espaço de tradução, constituído pelo saber filosófico, é um espaço de segunda ordem e coloca-se como condição para ek-sistência de um campo (filosófico) de instauração do sentido. A compreensibilidade, crê a atividade filosófica, somente se produz neste segundo espaço, neste campo re-duplicado que é o espaço da digitalização. Este espaço de tradução é indispensável, enquanto se constitui no modo humano de apreensibilidade do sentido e cuja eficácia é coextensiva à eficiência de um espelho ao fundar um campo ou espaço de reconhecimento, indicando que o humano necessita re ${ }^{6}$-pôr-(se) para compreender(se).

A experiência da compreensão se dá sempre num segundo momento, onde aparece traduzida. Esta tradução opera com a eficácia de um ato de re(a)presentação. Desta forma, nossa capacidade de compreensão é dependente da efetuação de uma operação de tradução. Il faut traduzir para um outro espaço, para um outro ambiente, para poder compreender. Este outro ambiente, que opera no espaço de metalinguagem, é uma tradução do espaço e do dado originais, que não seriam compreensiveis em si mesmos.

Podemos compreender, assim, o aforismo lacaniano sobre a filosofia: "Filóso$\mathrm{fo}^{7}$ é aquele que está interessado naquilo que todos estão interessados, sem sabê$10 " .8$

Contudo, é necessário evitar, a todo custo, no movimento de investigação filosófica, a implementação da linguagem como criadora ou instituidora de substância, o que permitiria objetificar a (noção de) realidade. Donde a inevitável necessidade da manutenção, ao ritmo da atividade filosófica como atividade especulativa, da constante tensão entre os dois campos dissimétricos ou des-coincidentes. De um lado, a ordem lógica da linguagem em função de sua eficácia sincrônica e, de outro lado, a sua ordem diacrônica que permite a produção ou instauração do sentido.

4 O mundo analógico do realismo ingênuo é re-construido digitalmente pela atividade filosófica. Verif. SANTUARIO, Luiz Carlos. Imaginarização do significante e forclusāo da culpabilidade. In: STEIN, E. (org.). Veritas, Porto Alegre, Edipucrs, v. 43, n. 1. 1998, p. 91-96.

5 Verbete: acrônimo [De acr(o)-1 +-ônimo.] S. m. 1. Palavra formada pela primeira letra (ou mais de uma) de cada uma das partes sucessivas de uma locução ou pela maioria das partes. Ex.: sonar [<so(und) na(vigation) r(anging)]. Aurélio eletrônico.

6 Para permitir a apreensão do movimento que o texto procurou descrever, foi utilizado o hifen em palavras como des-conhecimento, re-produção, con-fundir, co-incidente, re-posição, re-flexão, descobrir, des-velar.

7 Presumidamente, aquele que agiria sob o imperativo steiniano: "É mais importante organizar nossas incertezas em vez de impor nossas certezas."

8 LACAN, Jacques. Ecrits. Paris: Seuil, 1966, p. 807. 


\section{Lacan e o topos heideggeriano}

O xamanismo da analítica existencial heideggeriana, ao pôr em marcha sua máquina extratora da transcendentalidade que compõe o Dasein, em termos dos existenciais revelados pela marcha hermenêutica da ontologia fundamental, trabalha a partir do horizonte da compreensão medieval onde Ser é transcendentalis ${ }^{\theta}$ e desta forma revisa o ferramental kantiano que subjetivou o transcendental. Em função deste erro, Kant teria produzido (mesmo com a pretensa validação da dedução transcendental) a predicação das tábuas das categorias como ordenadoras do mundo. Porém, aos olhos heideggerianos, ${ }^{10}$ tudo isto, desnecessária e injustificadamente, para além do Dasein.

A plataforma construída, ou revelada, pela efetividade da marcha da fenomenologia-hermenêutica heideggeriana, ao instituir o Dasein como redutor último - a partir do qual, e em função do qual, devem ser remetidos os recorrentes temas de investigação da filosofia ${ }^{11}$ - pretende constituir-se no ambiente em relação ao qual todas as predicações de sentido devem ser remetidas. Este topos, este ambiente, que des-cobre o Ser do Dasein como cuidado e a temporalidade como o sentido de ser do Dasein, permite compreender a realidade como uma característica transcendental, não como algo existente, mas como algo que necessariamente remete ao Dasein. Este Dasein, cujo estatuto fundador não remete a uma existência humana meramente empirica e sociológica, mas cujo Ser é preparado a partir da temporalidade.

O elemento ou aspecto hermenêutico envolvido nesta decifração fenomenológica dos modos de ser do ser-aí (Dasein), aponta para o componente ativo do método hermenêutico que, em Ser e tempo, tem como objeto as condições existenciais da hermenêutica.

O empreendimento fenomenológico-hermenêutico, des-cobre o Dasein na clareira do Ser. O "Da" está agora no lugar da luz,12 da iluminação. A verdade, a partir daqui, não ocupa um topos excêntrico em relação ao Dasein. Ao invés disso, Heidegger pode dizer ${ }^{13}$ que existe verdade porque existe o Dasein. $\mathrm{Ou}$, de que o Dasein já está na verdade.

Em relação a este empreendimento heideggeriano que pretende constituir-se numa legítima revisão da metafísica ocidental, poder-se-ia compreender a alternativa heideggeriana (através do constructo Dasein) por analogia ao imperativo freudiano: onde era o isso, o eu deve advir, a partir do imperativo: onde eram as tábuas das categorias kantianas, o Dasein deve advir. A questão a determinar é se, nesta operação, ou nesta passagem, de deletar Kant e instalar Heidegger e a analítica existencial no $\mathrm{HD}^{14}$ da filosofia ocidental, o remédio (filosófico) não teria ficado forte demais, dado que todos os achados devem ser remetidos ao Dasein?

9 E, desta forma, deslocando a veritas transcendentalis para o campo humano do Dasein.

10 STEIN, Emildo. Seminário sobre a verdade. Porto Alegre: Vozes, 1993, p. 32-38.

11 Condiçōes de acesso à verdade, capacidade humana para conhecer e compreender, etc.

12 A metáfora da Luz foi, na tradição filosófica, elemento recorrente que metaforizava o caminho de acesso à verdade.

13 HEIDEGGER, Martin. El ser y el tiempo. México: Fondo de Cultura Económica, 1986, parágrafo 44.

$14 \mathrm{HD}=$ Hard disk. Disco rigido do computador que permite operar no ambiente digital, a partir dos programas e aplicativos ali instalados e existentes. 
Poder-se-ia, eventualmente, estender uma suspeita filosófica em relação a um certo contrabando criacionista, em Heidegger, dado que toda a realidade é coextensiva ao Dasein, o que implicaria em compreender o Dasein como ordenador. ${ }^{15}$ Talvez o narcisismo ${ }^{16}$ de Heidegger, onde a teoria parece atuar como sutura do Self heideggeriano, ${ }^{17}$ possa implicar na caraterização da analitica existencial como ação de partenogênese ${ }^{18}$ filosófica da auto-compreensão do Ser, a partir do Dasein.

A maquinaria da analítica existencial des-cobre o Dasein como adiante de si mesmo onde somente o Dasein se sabe finito. Entretanto, falta explicitar, como este espaço do saber é produzido. Falta explicitar, no meu entendimento, como se constitui a legitimidade da analítica existencial em predicar o modo de ser-prático do Dasein, desde-sempre no mundo; em instaurar esta plataforma operativa, este pano de fundo último, como bastidor, legitimador último de qualquer postulação filosófica. Neste sentido, esta ferramenta da analítica existencial, da descrição fenomenológica do Dasein, quer prescindir de qualquer outro tipo de predicação, ou de qualquer epistemologia ou método, quer seja estruturalista, analíticolingüístico, semiótico-transcendental, ${ }^{19}$ etc.

Quer nos parecer que a analítica existencial do Dasein constitui-se então apenas na re-posição, na re-produção ou metaforização, na linguagem, desde modode-ser-prático, ${ }^{20}$ onde já-sempre re-conheço o "verde da cadeira" dentre um modo de ser do Dasein onde já-sempre sei que esta cadeira é verde.

De que forma, então, validar filosoficamente a predicação da analítica existencial como elemento legitimador da plataforma última que permitiria a autenticação da leitura e da fundamentação de proposições filosóficas sem, incessantemente, retro-apelar para o chão filosófico da auto-compreensão (do Ser ${ }^{21}$ ), apenas re-posta na linguagem (não-reflexiva22) heideggeriana? "A contemplação fundamental husserliana que busca a razão na autoconsciência, dá lugar a novas autocontemplações de uma ontologia fundamental que encontra sua razão na compreensão do Ser."23

15 Como o francês diz ordinateur para definir o computador e seu modo de funcionamento, enquanto empreendimento que opera a partir do existencial (ambiente) digital.

16 Que se mostra a partir de uma grandiloqüência do eu-ideal filosófico, numa operação presque filosoficamente autista.

17 Ver: STEIN, Ernildo. Anamnese. Porto Alegre: Edipucrs, 1997, p. 128-130.

18 Sabemos ser o termo partenogênese bastante forte. Contudo, parece ser legitimo o seu emprego, a partir da constatação do caráter forclusivo da filosofia de Heidegger. Sobre isto ver também: (a) STEIN, Emildo. Anamnese. Porto Alegre: Edipucrs, 1997, p. 128-130; e (b) SANTUARIO, Luiz Carlos. Imaginarização do significante e forclusão da culpabilidade. In: STEIN, E.(org.). Veritas, Porto Alegre, Edipucrs, v. 43, n. 1, 1998, p. 95.

19 Verif. sobre isto o tipo de fundamentação últtima pretendida por Heidegger, in: STEIN, Emildo. Seminário sobre a verdade. Porto Alegre: Vozes, 1993, p. 170.

20 Stein, Seminário..., p. 40.

21 Id., ibid., p. 169.

22 Ver a critica de Apel a Heidegger em: APEL, Karl-Otto, La transformacion de la filosofia. Madrid: Taurus, 1985, v. 1, p. 119.

23 WALDENFELS, Bernhard. De Husserl a Derrida (Introducción a la fenomenologia). Barcelona: Paidós, 1997, p. 60. 
A dúvida filosófica aqui presente é a que estatuto fica reduzida a linguagem no topos heideggeriano, se ela constitui-se apenas em elemento de re-posição. Parece não haver, neste nível, um elemento de re-flexão sobre o próprio modo de operatividade da linguagem. Mesmo que se apele aí a uma transcendentalidade sem sujeito, ${ }^{24}$ ou, por afinidade eletiva, à aparente isotopia ${ }^{25} \mathrm{com}$ o fragmento 50 de Heráclito "que fala de um logos (no sentido de linguagem) que obriga o sujeito a apagar-se diante de uma verdade que ele enuncia e que o ultrapassa". ${ }^{26}$

De outra parte, para vir a habitar o espaço onde poder-se-ia constituir um diálogo entre o discurso da psicanálise e a maquinaria transcendental heideggeriana da analítica transcendental, deve-se ter presente, $a b$ initio, que se deveria falar apenas em afinidades eletivas e não em aproximações co-incidentes. ${ }^{27}$

Assim, por exemplo, para indicar o caráter excêntrico do sujeito em relação ao seu dito, Heidegger diz:

“[...] que o pensamento não se dá a si mesmo seu próprio começo e que antes da questão que coloca a filosofia há a solicitação da coisa que demanda se deixar pensar, mas que sempre escapa. Há, no dito, alguma coisa que se diz sob o modo de não dito, e onde a verdade, afetada por esta parte de sombra que lhe é necessária, deve ser compreendida como publicação pura e simples daquilo que não cessa de desaparecer. Há qualquer coisa que não se deixa pensar."28

Ainda no eixo das afinidades eletivas, "Lacan se alia então a Heidegger, ambos questionando o 'mundo' e mostrando-o como produzido a partir de algo que o excede: ato significante do ser, para Heidegger, e o jogo do significante puro, preso ao Nome-do-Pai e ao Outro, para Lacan". ${ }^{29}$

Através da psicanálise lacaniana, resistente à auto-instituição do Dasein como elemento formatador de sua própria plataforma operativa, poderíamos lançar um elemento de suspeita em relação ao ventriloquismo oracular heideggeriano alegando que

“[...] trata-se aqui daquele ser que só aparece no lampejo de um instante no vazio do verbo ser, e eu disse que ele formula sua questão ao sujeito. Oue significa isso? Ele não a coloca diante do sujeito, mas coloca-a no lugar do sujeito, ou seja, nesse lugar, ele coloca a questão com o sujeito, tal como se enuncia um problema com uma caneta e como o homem de Aristóteles pensava com sua alma." ${ }^{30}$

$\mathrm{O}$ argumento heideggeriano do ser-para-a-morte parece constituir-se em pura identidade abstrata, na medida em que a experiência não pode ser feita por nenhum Dasein ou, não pode singularizar-se em nenhum caso. Desta forma, em Heidegger, apesar do caráter de genialidade filosófica de certas de suas análises, pode-se inferir que o filósofo não produziu um ultrapassamento da dimensão ima-

24 Stein, op. cit., p. 167

25 Aqui no sentido de ocupar o mesmo topos.

26 ROUDINESCO, Elisabeth. Jacques Lacan, esboço de uma vida, história de um sistema de pensamento. São Paulo: Cia das Letras, 1994, p. 236.

27 Sobre isto ver também: SANTUARIO, Luiz Carlos. Imaginarização do significante e forclusão da culpabilidade. In: STEIN, E. (org.). Veritas, Porto Alegre, Edipucrs, v. 43, n. 1, 1998, p. 95.

28 Discours philosophique et discours analytique. Scilicet, Paris, Seuil, n. 6/7, 1976, p. 277 (notas de conferências e intervenções de Lacan feitas por terceiros).

29 JURANVILLE, Alain. Lacan e a filosofia. Rio de Janeiro: Jorge Zahar, 1987, p. 116.

30 LACAN. Jacques. Ecrits. Paris: Seuil, 1966, p. 524. 
ginária ${ }^{31}$ do sentido da facticidade ${ }^{32}$ A finitude, a partir da efetivação da existência temporal, institui a morte em mestre absoluto, em tribunal último da existência de um ser onde a realidade não reenvia senão ao simples fato de existir. "Para Heidegger a morte, enquanto que visada, assume numa existência decidida a tudo e a nada, o papel de eternidade." 33

Se, de um lado, a narrativa hegeliana do discurso do absoluto pode ser compreendida como resultado de uma dissociação do eu e de sua impotência a se sintetizar (uma vez que o discurso do absoluto se sintetiza perfeitamente), o discurso da finitude, em Heidegger, pode ser compreendido, a partir da psicanálise de Lacan, como resultado de uma recusa a aceder ao desejo, bem como de um recalcamento originário que, além disso, eles ignoram. ${ }^{34}$

Ainda que irredutível ao saber absoluto, o discurso da finitude se revela, tanto quanto o outro, inapto a descrever e prestar contas do sentido de seu próprio discurso, pois que a estrutura de seus discursos não é mais filosófica sendo que o sentido último pretendido que eles anunciam permanece ao nível do imaginário. 35

$\mathrm{Na}$ tentativa de compreensão do alcance epistêmico dos discursos de Lacan e Heidegger, Stein ${ }^{36}$ argumenta, referindo-se aos dois autores, que

"[...] os leitores anamorfóticos transformam os textos invertidos em suas teorias. Mas o próprio procedimento de inversão nã̃o é justificado nem segue regras universais. É que ele não pretende expor o sentido e o significado do texto. $\mathrm{O}$ autor quer expor-se no novo texto, e isto é mostrar sua teoria. O texto dependerá da teoria que dele se extrai. É a inversão anamorfótica produzindo seu resultado deformador e transformador."

Estes comentários, ou interpretações, das obras destes dois autores, foram produzidos visando compreender o caráter de originalidade presente nestes autores e na tentativa de delimitar o horizonte hermenêutico ${ }^{37}$ onde ambos se movimentam.

\section{Lacan e o ambiente gadameriano}

Em Gadamer, trata-se de compreender a linguagem como ambiente, ${ }^{38}$ modus, centro, elemento gerador originariamente constituidor de sentido, na medida em que a própria experiência do ser-humano somente é compreensível se adviña e remetida à linguagem. Contudo, exatamente por se constituir em campo instituidor de sentido, a linguagem é elemento, campo inesgotável e horizonte intransponivel: O ser-humano, toda sua constituição, e sua possibilidade mesma de instauração de sentido faz-se a partir da compreensão de que desde sempre nos movimentamos apenas (como limite e ambiente) no eixo da linguagem.

31 Sobre a indevida eficácia do imaginánio em Heidegger, ver também: STEIN, Ernildo. Anamnese. Porto Alegre: Edipucrs, 1997, p.128-133.

Discours philosophique et discours analytique. Scilicet, Paris, Seuil, n. 6/7, 1976, p. 277 (notas de conferências e intervenções de Lacan feitas por terceiros).

33 Op. cit., p. 274.

34 Op. cit., p. 276

35 Ibidem.

36 Stein. Anamnese, p. 124-125.

37 Op. cit., p. 121.

38 Proponho a tradução de Mitte (termo utilizado no original alemão) por ambiente para descrever e caracterizar a plataforma operativa a partit de onde o falante se posiciona ao acionar a linguagem. 
Daí a crítica e a necessidade de Aufhebung em relação a um certo positivismo metodológico das ciências humanas relativamente ao conceito de verdade que, para Gadamer, não é objeto de aproximação ou produção a partir do emprego de uma ferramenta metodológica, ${ }^{39}$ mas é algo que somente é atingível como acontecer. Este acontecer hermenêutico implica que não é o intérprete que, como elemento conhecedor, extrai, com meios metodológicos, o que realmente determinado texto quis dizer. O verdadeiro método vincula-se ao fazer da coisa mesma. E esta realmente acontece enquanto alguém se entrega à força do pensar. ${ }^{40}$

Gadamer insiste em que a hermenêutica é um aspecto universal da filosofia e não somente ä base metodológica das chamadas ciências do espírito. ${ }^{41}$

Com a perspectiva de poder ultrapassar e propor uma alternativa filosófica ao modelo especulativo-teleológico hegeliano, Gadamer aponta que Hegel compreende seu projeto e a si mesmo como aquele que efetivamente realiza uma consumação da filosofia grega do logos. Para Hegel, dialética constitui-se na submissão da linguagem a sua enunciação. Este conceito de enunciação, que implica no aguçamento dialético até a contradição, se coloca em rota absolutamente antípoda em relação àquilo que é visado pela essência da experiência hermenêutica e da lingüisticidade da experiência humana do mundo. A critica gadameriana a este projeto hegeliano consiste em denunciar o reducionismo hermenêutico-filosófico hegeliano, que apenas pretende extrair da linguagem o jogo reflexivo de suas determinações de pensamento, e elevá-lo através do caminho da mediação dialética, dentro da totalidade do saber sabido, até a autoconsciência do conceito. Para Gadamer, este reducionismo hegeliano implica na circunscrição da linguagem à dimensão do enunciado e, por conseguinte, não alcança a dimensão da expressão lingüística do mundo.42

Ao apontar as seqüelas filosóficas produzidas pela imperial e autofágica maquinaria hegeliana, onde não há mais horizonte a ser aberto através da experiência do contato humano com a linguagem - pois begriff ${ }^{3}$ e númeno, subsumidos numa totalidade conceitual, performam uma totalidade meta-inteligivel, além e aquém de qualquer interferência metodológica - resta ainda a Gadamer, após esta demarcação da distância que o separa do projeto hegeliano, indicar os impasses observados na ontologia fundamental de Heidegger.

A crítica gadameriana ao projeto de Heidegger, em Ser e tempo, revela que aquilo que Heidegger apresentou como ontologia fundamental do ser-aí não conseguiu superar, apesar de todas as análises temporais sobre o caráter de preocupação do ser-aí, sua auto-referência e, por conseguinte, o lugar ou estância central da autoconsciência. 44

39 GADAMER, Hans-George. Verdad y metodo I. Salamanca: Sígueme, 1996, p. 545.

40 Idem,.op. cit., p. 556

41 Idem, op. cit., p. 569.

42 Idem, op. cit., p. 560.

43 "O conceito (begriff) seria ai, então, a forma e o conteúdo do significante. Estaria, em sua operatividade, esgotando todo o sentido da presença do significante, naquilo que mais especificamente constitui sua presença" (SANTUARIO, Luiz Carlos. Hegel sem Lacan. Conjectura, Caxias do Sul, Educs, v. 3, n. 1, 1998, p. 101-119).

44 Gadamer, op. cit., p. 350. 
Para Gadamer, o elemento performativo que validaria filosoficamente a hermenêutica poderia ser compreendido como a inevitabilidade da auto-inclusão do interpretante no próprio processo descrito pela hermenêutica. Daí que ele pode afirmar que, mais importante que o método que utilizamos para fazer acontecer algo, é aquilo que acontece conosco, o que poderia ser caracterizado como a estrutura da experiência hermenêutica: aquilo que além do queremos que aconteça, isto acontece conosco. Para Gadamer, há um acontecer que é maior que o (acontecer) do Dasein. A linguagem que constitui o verdadeiro acontecer hermenêutico é (deixar) vir à fala o acontecido da tradição, através da ação da própria coisa.

Relativamente à possibilidade e necessidade de recuperação do sentido e significado da tradição, Gadamer introduz a dialética do ouvir como caminho para a realização da interpretação hermenêutica. Ouvir é ser interpelado por aquilo que é ouvido. Ouvir se abre à universalidade, se abre ao todo, se abre ao $\lambda \circ \gamma o \sigma$ (logos). Assim, o verdadeiro acontecer hermenêutico se dá quando efetivamente ouvimos a palavra que nos vem da tradição, como se ela se referisse a nós mesmos. ${ }^{45}$

Frente a isto poderíamos, provocativamente, indagar se não teria ocorrido uma espécie de "surdez hermenêutica" naquilo que permitiu a efetivação da dialética hegeliana, daquilo que se positivou em Hegel - que poderíamos chamar de "dialética do ver" - mas onde o sujeito efetuador do ato dialético não se põe, por estar abstraído do Processo. 46

Contrariamente à obsessiva visada te(le)ológica hegeliana, Gadamer aponta que é preciso ter presente que tudo o que uma linguagem desencadeia consigo mesma, remete sempre para além do enunciado como tal. E, no processo de instauração do sentido para além do (conteúdo do) dito do sujeito, algo fica sempre sem ser dito. Relativamente a este aspecto e, se esta sentença se pode afirmar como tal, isto é, se ela efetivamente se pode fundamentar, seria instigante pensar na possibilidade de Tugendhat ter jogado em vão sua vida filosófica, na medida em que procurou extrair, através das ferramentas da filosofia analítica da linguagem, o efetivo sentido do enunciado, na primeira fase de sua obra ${ }^{47}$ na filosofia teórica e, depois, na Ética.

Por afinidade eletiva, a descoberta gadameriana do meta-horizonte da linguagem poderia ser compreendida como consoante ao campo lacaniano, onde "o significante, por sua natureza, sempre se antecipa ao sentido, desdobrando como que adiante dele sua dimensão". 48

$\mathrm{Na}$ medida em que método (inclusive analítico ${ }^{49}$ ) constitui-se em regra para regrar o acontecimento, o procedimento da hermenêutica gadameriana compre-

45 Idem, p. 553.

46 Processo aqui de auto-inserção mais feliz, para o sujeito, que aquele em que viu se subsumido o personagem Joseph K., do Processo de Kafka.

47 Até sua obra Traditional and analytical philosophy - lectures on the philosophy of language (Cambridge Univ. Press, 1982).

48 Lacan, Ecrits, p. 505.

49 Sob o ponto de vista do empreendimento hermenêutico, é possivel denunciar o reducionismo filosófico operado pela método analítico que positiva e objetiva este espaço de sentido onde as questōes filosóficas se dão. 
ende que regra não pode con-fundir-se com jogo, que é relativo ao acontecimento que acontece conosco, quando jogamos $\underline{0}$ jogo da linguagem. ${ }^{50}$ Gadamer compreende que a hermenêutica, e sua tarefa, não é problema de método.

O horizonte ${ }^{51}$ da tradição, ao trazer o elemento de pertença que se dá no e para o interpretante, elemento ineliminável da formatação da empreitada filosófica da hermenêutica gadameriana, funcionando ali como instrumento produtor e doador de sentido ao dito do sujeito filosófico, embora atuando como algo não efetivável na história/tradição, implica em que, no núcleo do processo de compreender, haja sempre uma referência a si-mesmo, ao sujeito. Este sujeito, desta forma, escapa ao canibalismo filosófico da máquina hegeliana e sua obsessiva metareferência ao Absoluto. Obsessão filosófica engendrada pela produção de um saber da história guiado por uma redenção. ${ }^{52}$

Desta forma, a hermenêutica consolida sua proposição de que o sujeito sempre "arrisca sua vida filosófica" e, inevitavelmente, põe-se em jogo ao acionar o jogo da linguagem e da interpretação. Assim, fica assegurado o aspecto do elemento hermenêutico do sujeito que analisa ou interpreta, pela presença da autoimplicação do sujeito que compreende no próprio ato de compreender.

A compreensão gadameriana da linguagem como ambiente aponta para a experiência radical da hermenêutica que é a experiência da finitude. Gadamer aponta que "nos guiamos pelo fenômeno hermenêutico, e seu fundamento mais determinante que é precisamente a finitude de nossa experiência histórica". ${ }^{53}$

"Ser histórico significa não esgotar-se nunca no saber-se. Todo saber-se procede de uma predeterminação histórica que podemos chamar com Hegel 'substância', porque suporta toda opinião e comportamento subjetivo e em conseqüência prefigura e limita toda possibilidade de compreender uma tradição em sua alteridade histórica. Diante disto, a tarefa da hermenêutica filosófica pode caracterizar-se como segue: deve refazer o caminho da fenomenologia do Espírito hegeliana enquanto que em toda subjetividade se mostra a substancialidade que a determina." 54

A operacionalidade da dialética gadameriana compreenderá a substancialidade (tradição, pré-juizos, pré-conceitos que se escondem) como determinante da subjetividade. Neste sentido, a eficácia da hermenêutica consistirá em reproduzir ${ }^{55}$ o movimento circular, através do dispositivo do círculo hermenêutico, onde o sujeito se des-cobre sujeito, pois se descobre filiado a uma tradição, sempre no interior da linguagem, pois a linguagem é ela mesma determinante de toda pertença do sujeito. Daí que a teleologia do begriff é efetivada, na hermenêutica, às avessas do odós hegeliano.

50 Imprescindivel aqui ter absolutamente presente a distância filosófica que separaria o conceito de "jogo de linguagem", no Wittgenstein das Investigaçōes Filosóficas, da compreensão aqui presente.

51 "The interpreter of a text from a past culture belongs to and is conditioned by its own different culture; he is an effective-historical consciousness who views the past and its remnants from a particular horizon, involving a particular pre-understanding. His understanding thus involves an interplay between past and present, a fusion of horizons" (HONDERICH, Ted, ed. The Oxford companion to philosophy. Oxford, New York: Oxford University Press, 1995, p. 303).

O hífen faz-se necessário aqui apara apontar o caminho do processo. 
Assim, pensar quer dizer precisamente desenvolver uma coisa em sua própria conseqüência. Para isto é necessário afastar idéias e imagens que costumeiramente nos aparecem e ater-se estritamente ao pensamento. Para Gadamer, isto é 0 que, desde a filosofia grega, se chamou de dialética. ${ }^{56}$ Fica assegurado, desde este patamar, o dispositivo dialético como inextrincavelmente ligado ao empreendimento hermenêutico. Porém o dialético, a partir da compreensão dos gregos, de que se trata do movimento da coisa mesma que o pensamento percebe, e não movimento do pensamento. ${ }^{57}$

Para Gadamer, a constituição finita do sujeito filosófico, co-extensiva ao pertencimento à experiência radical da linguagem, experiência da finitude humana, nos impede e previne, a priori, da possibilidade de nos utilizarmos da palavra de modo a produzir um conhecimento absoluto e um universo de entes objetivados, como, por exemplo, na matemática, graças ao cálculo. "Nem um espírito infinito nem uma vontade infinita estão capacitados para sobrepassar a forma de experiência do ser adequada a nossa finitude." 58

Para Gadamer, na experiência hermenêutica se encontra algo parecido a uma dialética, um fazer da coisa mesma, um fazer que a diferencia da metodologia da ciência moderna, é um padecer, um compreender, um acontecer. Gadamer compreende que a hermenêutica, e sua tarefa, não é problema de método.

A constituição lingüística e finita do ser humano, modus de produção da subjetividade filosófica, implica que a finitude, nosso pertencimento à linguagem, aponta para algo além da linguagem, enquanto elemento de infinitude. Por esta modalidade de prova quase indireta, é possível caraterizar o trabalho da hermenêutica e o trabalho da filosofia, como inexoravelmente ligados ao movimento especulativo. Esta estrutura especulativa da linguagem consiste em não ser ela cópia de algo que está dado cọm fixidez, mas num aceder à linguagem na qual se anuncia um todo de sentido. ${ }^{59}$

Desta forma, devemos compreender toda interpretação como especulativa em sua própria realização efetiva e acima da autoconsciência metodológica; isto é o que emerge da lingüisticidade da interpretação. Daí que, operando na plataforma hermenêutica, nenhum interpretante pode ter a última palavra, pois a experiência hermenêutica aponta para o caráter interminavelmente aberto do acontecer de sentido de que participa. 60

Se podemos compreender o estabelecimento da maioridade filosófica em Hegel como produzida pelo contrabando (ou contravenção) filosófico onde o conceito já fagocitou os objetos do mundo, dado que o begriff já contém em si o objeto, seu significado e seu des-velamento histórico, a eventual minoridade filosófica da hermenêutica dar-se-ia em função que ela não define, (por prescindir de um modo exterior de prova), sua tábua categorial, seu modo operativo, e a gênese da precisão de suas predicações lingüisticas.

57 Idem, p. 551.

58 Idem, p. 548

59 Idem, p. 567

60 Idem, p. 565. 
Se organizar as nossas incertezas implica em expor a(s) moldura(s) nas quais os problemas e sua colocação possam estar ancorados, bem como, se possivel, as regras que foram utilizadas para a produção destas molduras, a hermenêutica gadameriana consegue, com brilhantismo filosófico, ao mesmo tempo que expõe a incerteza proveniente do modo de constituição finito do sujeito filosófico, produzir um grau acurado de certeza ao mostrar a eficácia da lavra hermenêutica e a produção de inteligibilidade conceitual que daí brota.

Contudo, against ${ }^{61}$ ou para além de Gadamer e da tentativa gadameriana de instituição da tradição como fundo de sentido último, ou "metalinguagem primeira" do binômio tradição-fala individual do sujeito inscrita na trama/horizonte da tradição, Lacan aponta que

"[...] também o sujeito, se pode parecer servo da linguagem, o é ainda mais de um discurso em cujo movimento universal seu lugar já está inscrito em seu nascimento, nem que seja sob a forma de seu nome próprio. A referência à experiência da comunidade e da substância desse discurso não resolve nada. Pois essa experiência adquire sụa dimensão essencial na tradição instaurada por esse discurso. Essa tradição, muito antes que nela se inscreva o drama histórico, funda as estruturas elementares da cultura. E essas mesmas estruturas revelam uma ordenação das trocas que, embora inconsciente, é inconcebivel fora das permutações autorizadas pela linguagem." "62

\section{Filosofia e psicanálise}

"A primeira atitude filosófica frente ao saber da psicanálișe seria de considerar o freudismo uma filosofia da natureza, destinado a justificar as superestruturas éticas por uma ordem psiquico-biológica. Substituindo o pecado original pelas psiconeuroses, o Freudismo nada mais seria que um dogmatismo que substitui o poder clerical por um poder médico onde a idéia de um salvador se encontra excluida. Esta primeira atitude filosófica, frente ao saber da psicanálise, é tributária de uma herança cartesiana que reduz aquilo que é ao sistema de representação de uma consciênçia. Desta forma, o inconsciente é relegado ao plano da res extensa cartesiana o que permite confundir o saber freudiano com um determinismo biológico.

"Uma segunda atitude filosófica, melhor intencionada, considera que o saber da psicanálise possui sentido, mas que ainda the faltaria um sentido adicional para que ela pudesse, finalmente, fazer sentido. Conjugando à maneira kantiana o (assim considerado) realismo empírico de Freud e um idealismo transcendental, que fundaria este realismo, agora num novo patamar de uma consciência que constituiria o campo do inconsciente a partir de uma hermenêtica transcendental, que permitiria escapar a uma interpretação ingênua do realismo freudiano. Desta forma, não existiria inconsciente como tal, mas apenas as démarches hermenêuticas (que) são constitutivas do inconsciente.

"Uma terceira atitude, dos fenomenólogos de boa vontade que crêem ter encontrado no freudismo uma confirmação de suas investigações eidéticas. Aproximando a Traumdeutung de Freud das recherches logiques de Husserl e, considerando a consciência como intencionalidade, eles pensam que o inconsciente é um modo particular de intencionalidade e que deve necessariamente referir-se à

\footnotetext{
61 No sentido de contrario a.
}

62 Lacan, Ecrits, p. 499 
ordem da consciência, isto é, a uma ordem constitutiva de sentido. Para eles, teria faltado a Freud este conceito de intencionalidade. Situados no patamar da fenomenologia husserliana e a partir dela, numa perspectiva que não reduz a verdade do homem ao sujeito transcendental, não existiria lugar no idealismo transcendental para o inconsciente. Excluído do campo da consciência, ele escaparia a uma investigação fenomenológica estrita. Sendo irredutível ao estatuto de noema, ele constitui um não-senso, um escândalo ontológico. A realidade do inconsciente, para esta terceira corrente, seria fundada a partir das análises husserlianas, considerandose que a consciência não é pura transparência a si mesma e que toda consciência implica um campo de dados atualizáveis, eles podem aproximar a noção de inconsciente daquilo que Husserl chama potencialidades da vida intencional."63

Estas três posições filosóficas, frente ao saber trazido pelo discurso da psicanálise, nos mostram de que forma o discurso filosófico pretende ser um discurso unívoco "se compreendendo a si mesmo". Esta pretensão coloca o ser como sendo por si (a partir de si) e o considera como uma metalinguagem. ${ }^{64}$

Com relação, por exemplo, à terceira posição acima descrita, a da atitude dos fenomenólogos, fica claramente indicada a insuficiência da fenomenologia pois, embora sua abertura ao inatual e ao pré-reflexivo não consegue escapar ao círculo de correlações entre noema e noese. Assim, ainda que o inconsciente fale nos estados de sofrimento, e.g. fobia e delírio, o sujeito não consegue re-conhecer 65 aquilo que the é próprio, i. é, não consegue reconhecê-las como a revelação de uma verdade que lhe é singular. ${ }^{66}$

A filosofia pretende ser atividade autônoma e instauradora da Lei a partir do qual se instauraria a legibilidade do mundo real, a partir dos significantes por ela instalados. Contudo ignora solene e ostensivamente a instância do desejo (como aquém da mediação pela sua Lei) como elemento instaurador da possibilidade de abertura de um mundo para o sujeito.

Vemos, assim, de que forma a verdade totalmente desenvolvida e realizada da filosofia pretende reunir67 o ponto de partida, ao preço da exclusão do desejo. Exclusão necessária para que se estabeleça a tão decantada coerência filosófica. ${ }^{68}$

Por outra parte, o discurso psicanalítico mostra que a falsa plenitude do discurso do absoluto se funda sobre uma subordinação do desejo à verdade discursivamente desenvolvida, e que le malheur do discurso da finitude provêm da manutenção abstrata de um desejo indeterminado, assim como de recusar assumir a particularidade deste desejo. ${ }^{69}$

A álgebra lacaniana nos ensina que aquilo que torna possível a própria existência da linguagem é este lugar vazio (place vide) que torna possível dizer-se qualquer coisa com linguagem, e que longe de constituir-se num saber é apenas efeito da existência do significante. ${ }^{70}$

63 Discours..., p. 258.

64 Op. cit., p. 290.

65 Aqui, no sentido de constituir um espaço de saber para si.

66 Discours..., p. 261.

67 Rejoindre.

68 Op. cit., p. 258

69 Op. cit., p. 291.

70 Op. cit., p. 290. 
Embora subtraído à consciência, este saber não é menos estruturado como uma linguagem, mas de uma estrutura que não se instaura de nenhuma parte, senão de um ponto de falta. Sendo distinto do conceito, ainda que sendo presente no interior do discurso, esta presença não se deixa apreender, em nenhum momento, de maneira discursiva. Ele não é dado em nenhuma parte como um em-si conhecivel..$^{71}$

Para a psicanálise trata-se de compreender o sujeito como cindido de si mesmo pela presença de um desejo que lhe é desconhecido. Desejo este que apenas vai se materializando, metonimicamente, em objetos avatares miragens/ilusão dispostos no plano (achatado) da oftalmologia. (objetos sem densidade de temporalidade, apenas vistos no eixo bidimensional cartesiano).

O suposto sujeito pleno da filosofia é interrogado por Lacan: "A estrutura da linguagem uma vez reconhecida no inconsciente, que tipo de sujeito podemos nós concebermos?"72

Trata-se de compreender o sujeito, a partir daí, como sujeito do inconsciente. Aquele que ek-siste ${ }^{73}$ em função das leis de articulação do discurso do inconsciente. Assim, o moi fica compreendido como efetuador de uma função alienante por estar relacionado a uma forma ortopédica da totalidade, a qual o sujeito se identifica a partir do momento do estágio do espelho. ${ }^{74}$

"[...] estrutural do sujeito, o complexo de castração constitui neste essencialmente a margem que todo pensamento evitou, saltou, contornou ou encobriu, todas as vezes em que aparentemente conseguiu apoiar-se num circulo, ${ }^{75}$ fosse ele dialético ou matemático." 76,77

Assim, a castração simbólica, equivalente à entrada no mundo da linguagem, institui o discurso como lugar da falta e exatamente por isto ela constitui, ou produz, um lapso, ou intervalo, entre uma "realidade" (lá onde eu sou) fundada sob a diferença dos sexos e um "eu penso" onde esta diferença não é articulável e onde o discurso não poderia capturar e compreender o conteúdo mesmo como falta a jouir dans la réalité. O discurso do mestre e o discurso filosófico, que é uma variante deste, nada produzem desta castração simbólica. O discurso filosófico permanece por assim dizer ao nível da castração imaginária, que funciona como uma denegação da castração simbólica. ${ }^{78}$

Desta forma, o discurso filosófico, por mover-se ao nível da castração imaginária, não tem a necessidade de representar a diferença de sexos, diferença que institui a des-identidade ou des-coincidência entre significante e realidade. $\mathrm{O}$ que funda a famosa coerência filosófica é o desconhecimento do desejo, elemento inaugural do sujeito e de sua fala. ${ }^{79}$

71 Ibidem.

Lacan, Ecrits, p. 800.

No sentido de que existe fora de si-mesmo; fora de seu centro.

Discours..., p. 285-286.

Grifo meu.

Lacan, Ecrits, p. 835.

(ou hermenêutico, acrescentaria eu.)

Discours..., p. 288.

Ibidem. 
A fala do filósofo e o saber que ela procura instituir absolutamente ignoram o estatuto do inconsciente, que implica ser falado desde um outro lugar, o que o cogito cartesiano desconhece. Isto quer dizer aqui que o homem é um ser falante, e que ele procura revelar a falta que o constitui: não apenas a falta absoluta, a qual se pretenderia corresponder uma pretendida angústia metafísica, ${ }^{80}$ nem a falta em relação à qual se lutaria tenazmente para ultrapassar e assim colmatar o ser sob a espécie de uma ontologia do nada; mas falta de um objeto no campo do Autre ${ }^{81}$ de um objeto onde a perda de toda especularização e de toda significação fez surgir um sujeito que, se identificando ao saber, ${ }^{82}$ vem recobrir o lugar desta perda, chegando até o ponto de bloquear a existência. ${ }^{83}$

É ao preço desta perda que se estabelece a identidade do pensar e esta perda não reconhecida faz o discurso filosófico permanecer, em função de sua estrutura, numa perpétua identidade a seu imaginário. ${ }^{84}$ Esta identidade imaginária nada mais é que uma petição sintomática que, através da busca do estado adâmico antes da queda, nada concretiza a não ser abraçar uma fantasia destinada a assegurar ao sujeito uma falsa plenitude. ${ }^{85}$ Configura-se assim, para além de todo cartesianismo, uma situação aporética da relação do sujeito a um saber que o ultrapassa. ${ }^{86}$

O discurso filosófico encontra sua eficácia na atribuição de uma equivalência entre o pensamento e o ser. Para o discurso psicanalítico há um saber que não se sabe, um saber que transborda e ultrapassa aquele que se sabe: este saber é o saber do Autre, enquanto que lugar onde o significante se coloca, e sem o qual nenhuma dimensão de verdade se revela. ${ }^{87}$

Frente a este saber, o saber do inconsciente não se institui como discurso real senão que se manifesta como impossivel ${ }^{88}$ de circunscrever. Compreende-se a experiência do nomear como visando à produção do verdadeiro. Daí que se compreende que nomear é sublimar, agir como letra, abrir passagem para si nesta via obstruída de um saber que lhe é anterior. ${ }^{89}$ Para a psicanálise, este sujeito que visa a sublimação, através do recurso à letra, é ele próprio uma superfície ${ }^{90}$ onde opera o significantẹ e suas leịs de arțiculação,: 91 "O inconsciente, a partir de Freud, é uma cadeia de significantes que em algum lugar(numa outra cena, escreve ele)

80 Pense-se aqui para além do châo filosófico da fundamentação heideggeriana e a pretensa posição da angústia como cogito metodológico.

81 A ordem simbólica.

82 Grifo meu.

83 Discours..., p. 288.

84 Ibidem.

85 Op. cit., p. 289.

89 KAUFFMAN, P. Dicionánio enciclopédico de psicanálise - o legado de Freud e Lacan. Rio de Janeiro: Jorge Zahar, 1996, p. 373.

90 Uma plataforma digital, diria eu.

91 Kauffman, op. cit., p. 528. 
se repete e insiste, para interferir nọ cortes que lhe oferece o discurso efetivo e na cogitação a que ele dá forma."92

A experiência analítica descobre, no inconsciente, toda a estrutura da linguagem o que permite relativizar a tese corrente das des-leituras ou das re-leituras de que o inconsciente é a sede dos instintos. ${ }^{93}$

Esta eficácia da letra, como "suporte material que o discurso concreto toma emprestado da linguagem", como o diz Lacan, permite supor que a "linguagem não se confunda com as diversas funções somáticas e psíquicas que a desservem no sujeito falante. Pela razão primeira que a linguagem com sua estrutura, preexiste à entrada de cada sujeito num momento de seu desenvolvimento mental". ${ }^{94}$

Em relação ao binômio significante/significado, ou à secular questão filosófica do nosso acesso a um mundo povoado de objetos, devemos considerar que

“[...] se formos discernir na linguagem a constituição do objeto, só poderemos constatar que ela se encontra apenas no nível do conceito, bem diferente de qualquer nominativo, e que a coisa, evidentemente ao se reduzir ao nome, cinde-se no duplo raio divergente: $o$ da causa em que ela encortrou abrigo em nossa língua e o do nada ao qual abandonou sua veste latina $(\mathrm{rem})$. Essas considerações, por mais existentes que sejam para o filósofo, desviam-nos do lugar onde a linguagem nos interroga sobre sua natureza. E fracassaremos em sustentar sua questão enquanto não nos tivermos livrado da ilusão de que o significante atende à função de representar o significado, ou, melhor dizendo: de que o significante tem de responder por sua existência a titulo de uma significação qualquer. ${ }^{95}$

Trata-se, para o discurso da psicanálise, da existência de um real inabsorvível e que, todas as investigações imaginárias de harmonia, com as quais está envolvido o saber da filosofia, quer se refiram à idéia de cosmo ou à idéia do amor, idéia do bem, idéias das quais sabemos que a forma unificadora e humanizadora não se estabelece senão fazendo barragem ao desejo.

A psicanálise define o real como o impossivel e, nesta perspectiva, o real se apresenta como aberto entre o simbólico $0^{96}$ e a realidade, e é esta abertura que caracteriza a impossibilidade de dizer todo o verdadeiro sobre o verdadeiro. Assim, a verdade total, a que aspira dizer a filosofia, não se institui senão ao preço da redução do desejo à simples contingência corporal. ${ }^{97}$

"A esquisitice da criatura que coroa a ordem animal está em ter uma organização biológica desnaturada por um sistema que nada mais tem de fisiológico, já que ele rompe com uma adaptação ao mundo, regulada, até então, por signos, certamente não por significantes." 98

\footnotetext{
92 Lacan, Ecrits, p. 813.

93 Idem, p. 498.

94 Ibidem.

95 Lacan, op. cit., p. 501.
}

96 Simbólico, como um dos registros instituidos pela álgebra lacaniana para pensar a estrutura que suporta a existência humana. Os outros são o Imaginário e o Real.

97 Discours..., p. 291

98 MELMAN, Charles. Novos estudos sobre a histeria. Porto Alegre: Artes Médicas, 1985, p. 13. 
A psicanálise lacaniana institui um campo conceitual novo ao dizer que a inteligibilidade do fenômeno não é dada pela (presença da) coisa (do objeto) mas pela antecipação ( da eficácia) do signo.

O significante, para a psicanálise, é semioticamente carregado e, contrariamente ao postulado pela lingüística, não é (diretamente) suporte de significado, posto que o modo próprio de eficácia e funcionamento do significante dá-se em função de estar conectado, primordialmente, a outro significante, em cadeia, (eslabón, chain) e não a um significado (imediato) exterior à cadeia.

Desta forma, a opacidade do mundo empírico (qua mundo oftálmico dos objetos) apresentar-se-ia como necessária, para que o significante possa aí intervir fundando a presença egóica e imaginária do sujeito, que viria ali para fundar, posteriormente, geocentricamente e cartesianamente o mundo.

"O grande salto que a análise lacaniana promoveu em relação à tradição filosófica foi justamente retirar o sujeito de dentro do homem, expulsar esse 'homenzinho' que o pensamento clássico supôs definir interiormente o eu. Lacan desmonta esse cogito cartesiano de que a perspectiva geométrica do Renascimento é o correspondente plástico e reconduz a noção de sujeito à sua dependência significante: o sujeito já não é mais essa instância fundadora e casual do discurso idealista, mas tão simplesmente um efeito da cadeia do discurso." 99

Relativamente ao estabelecimento desta tese há um escândalo na gênese (do discurso lacaniano) relacionável ao conceito de histeria, que poderia ser lida em 3 tempos diversos:

a) benigna: (e.g.) filosofia, qua discurso que visaria falar do Um. (Real inassimilável?)

b) clínica: se apresenta como sintoma (uso do organismo ${ }^{100}$ ) para instituir (fundar o discurso) do nome-do-pai. (o Um).

"O sintoma histérico é evidentemente a emergência do real sob a forma de sintoma, na medida em que a imagem do corpo é o que vem se desfazer, o que vem pesar, e faz com que o corpo emerja enquanto real. Constata-se que Freud não se interessou senão por isso, na medida em que esse real se verificou ser para ele não a manifestação de algum poder sobrenatural, mas a manifestação de um real enquanto lugar de um saber. Foi isso que apaixonou Freud."101

c) histeria perfeita: Jacques-Marie Lacan: (que se apresentaria como) histeria perfeita em função de sua ação lingüística que não se dirigiria (sintomaticamente) a produção/instauração do discurso do Autre, mas à instauração do (sentido do) significante em seu campo hermenêutico próprio. (Lingüisteria qua registro/campo hermenêutico específico onde se articularia o sentido do significante e de seus efeitos). Uma compreensão "filosófica" possível da noção de lingüisteria102 seria a

99 MACHADO, Arlindo. Psicanálise e cinema. In: CHALHUB, Samira (org.) Psicanálise e o contemporâneo. São Paulo: Hacker, 1996, p. 75.

100 Organismo compreendido aqui enquanto dispositivo regulado pela pura fisiologia, como antípoda a corpo erógeno, que é o organismo animado pelo desejo inconsciente.

${ }^{101}$ Melman, op. cit., p. 6.

102 Ver também a abordagem da noção de lingüisteria em Lacan. In: Stein, Anamnese, p. 128-130. 
de um espaço e tempo próprios, constituídos pela "tensão" do uso e do sentido do significante no discurso lacaniano como co-originários do processo de constituição de sentido, visando recuperar o significado da presença do significante no e para o campo humano. "Ocorre então que nosso caminho nos conduz ao estudo do inconsciente, ou seja, do sistema que, sem o seu conhecimento, pauta o destino do fala-ser." 103

"O termo inconsciente é tanto mais inadequado quando se encontra nesse lugar que habita o saber. Ora, o saber, como sabemos muito bem, não está do lado do sujeito. Trata-se, neste lugar do inconsciente, não apenas, do saber do gozo, mas também primordialmente, do saber que pauta todas as nossas percepções. Teremos que retornar a esse traço, e podemos notar desde já que, no par de opostos conscienteinconsciente, é o consciente, ou o que chamamos assim, que é regido pelo inconsciente. Da mesma forma, o enigma, o mistério, estaria mais do lado do que acede à nossa consciência do que nos é permitido saber e cuja soma, afinal, pode parecer cada vez mais bastante enigmática."104

O caso Lacan poderia ser lido como um hegelianismo da diferença? e o caso Hegel como uma "psicose da identidade"? na medida em que este toma o mundo (instância do significado) idêntico ao sujeito. O que é pura diferença (mundo diferente do sujeito) e (significante diferente de significado) torna-se isomórfico e isonômico um ao outro. O que sobrevive de ser apenas pura diferença e deve permanecer como diferença (como não co-respondente), objetos do "mundo" e sujeito oftalmológico, em Hegel tornar-se-ia psicoticamente idêntico. "Se o simbólico é uma dimensão humana, ou uma condição humana positiva porque socializa o homem e organiza sua existência, em contrapartida, ele apresenta a desvantagem de formalizar a existência vital do indivíduo, de a canalizar e reduzir."105

Se a filosofia é uma instância de meta-representação, de re-produção do sentido (significado), haveria um método/modelo de meta-representação para o campo conceitual (poder-se-ia dizer semiótico?) instituído a partir da psicanálise?

Qual o campo/espaço onde se instaura o sentido do "campo conceitual" da psicanálise? Na pura presença imanente de seus conceitos? (linguagem privada?); no campo da re-construção das implicações filosóficas de sua eficácia e de seu alcance? Com qual categoria de conceitos se (pode) manejar o campo (conceitual) da psicanálise?

Poder-se-ia pensar a psicanálise como um momento ou instância de linguagem privada, no sentido de que esta estaria de posse de uma linguagem que só ela possa compreender e só ela possa formular? Podemos pensar que para que possa instituir-se como campo hermenêutico válido, ela deve poder invalidar esta imputação. Caso obtenha eficácia em dar provas de seu não pertencimento à esfera da linguagem privada, ela poderia ser considerada uma hermenêutica do desvisível, posto que o discurso alí instituído não instaura um campo de objetos que seriam retraçáveis pela aposição quer de uma epistemologia quer de uma

103 Melman, op. cit., p. 3.

104 Idem, p. 5.

105 LEMAIRE, Anika. Jacques Lacan - uma introdução. Rio de Janeiro: Campus, 1989, p. 103. 
hermenêutica (positiva) ou de uma análise lingüística nos moldes propostos por Tugendhat, dado que a cadeia (do) significante engendra sentido a partir de suas próprias leis de articulação (funcionamento) ${ }^{106}$ o significado (produzido-advindo) não seria algo remissivel a um campo de conteúdos, a ser investigado por uma hermenêutica da positividade.

"[...] dizer que o sujeito é o efeito ou o resultado ( a linguagem é a causa do sujeito), exige uma lógica, a 'lógica do significante'. Se o sujeito, na acepção lacaniana, só se pode constituir no jogo simbólico por uma divisão, em que para aparecer como sujeito ele precisa ser excluído ou mascarado pelo significante, conclui-se que ele só se torna alguém (um) pela sua constituição como menos-que-um (zero) [...] o sujeito é portanto o objeto separado de si, anulado; excluído do discurso que ele produz. Para a psicanálise moderna, ele é justamente o que toma o lugar do objeto excluido, sutura a sua ausência." 107

\section{Para não concluir}

A ordem do mundo animal - de instauração co-extensiva à eficácia do instinto) é regida pelo pleno des-conhecimento. Isto é, fica vedado à girafa, por exemplo, a possibilidade de ela produzir um saber sobre o que the permite situar-se quotidianamente no mundo de seus objetos: grama, cerca, etc.

Parece que, da mesma forma, a ordem do mundo do humano - de instauração co-extensiva à eficácia do símbolo - instituída a partir do inevitável contacto com o significante e do acesso à linguagem, permite, por um lado, produzir uma atividade consciente, de re-posição de sua própria ek-sistência, através da reduplicaçăo de sua experiência, campo que a filosofia ocidental procura habitar de modo absoluto, como metalinguagem última deste segundo momento da certeza. Contudo, dado que a filosofia des-conhece os equivocos de sua própria autoparturiação, isto é, não sabe contar-se por um erro de nascimento (partenogênese heideggeriana, por exemplo [...]) não permite ao sujeito constituir um saber acerca do modo de instauração de seu mundo, ou do modo como ele veio a habitar este mundo, já que foi inserido numa trama semiótica, pré-figurada. Se disto há conhecimento, disto não se pode produzir nenhum saber ${ }^{108}$ Seria então possivel e necessário pensar-se na necessidade de uma hermenêutica do des-visivel, numa hermenêtica semiótica que pudesse mapear as estruturas existenciais e seus modos de constituição, para além do manejo cartesiano/kantiano/heideggeriano (que des-conhecem o desejo como fundador do humano)? Esta outra hermenêtica estaria implicada numa Wirklichkeit semiótica e semi-óticà. ${ }^{109}$

Se exatamente o que nos move é a falta do objeto (insabida, pois não habita um espaço representacional) que se manifesta sintomaticamente na linguagem, a linguagem da filosofia para recobrir o todo, e atingiri10 a verdade, deve excluir o

${ }^{106}$ Donc-o significante é anterior ao sujeito:

107 Machado, op. cit., p. 76.

108 Lacan, Ecrits, p. 818.

${ }^{109}$ Semi-ótica referindo-se a que é indisponivel à verificação oftalmológica.

${ }^{110} \mathrm{Ou}$ a-tingir, no sentido de quem pretende tingir a verdade com as cores da linguagem que emprega. 
desejo, como estrutura prévia (não representacional) de sentido. Em relação a esta presunção de edição do real, obsessão milenar da atitude filosófica, a peste freudiana, através de Lacan nos previne de que há, àpenas, efeitos de realidade, tributários da pré-eficácia simbólica e semiótica que inauguram um sujeito falante, inclusive o sujeito filosófico.

A abordagem da noção de realidade deve ser perseguida em relação a esta eficácia semiótica, como sugerido por Lacan: "[Alguém] chamado Charles Sanders Peirce construiu sua lógica que, pelo fato do acento colocado na relação, faz dela uma lógica ternária. É [esta] exatamente a mesma via que eu sigo [...].”111

\section{Referências bibliográficas}

APEL, Karl-Otto. La transformación de la filosofia. Madrid: Taurus, 1985. v. 1.

GADAMER, Hans-George. Verdad y metodo I, Salamanca: Sígueme, 1996.

GAUVIN, J. O discurso da filosofia sistemática. Coimbra: Almedina. 1973.

HEIDEGGER, Martin. El ser y el tiempo. México: Fondo de Cultura Económica, 1986.

HONDERICH, Ted (ed.) The Oxford companion to philosophy. Oxford, New York: Oxford University

Press, 1995.

JURANVILLE, Alain. Lacan e a filosofia. Rio de Janeiro: Jorge Zahar, 1987.

KAUFFMAN, P. Dicionário enciclopédico de psicanálise-o legado de Freud e Lacan. Rio de Janeiro: Jorge Zahar Editor. 1996.

LACAN. Jacques. Ecrits. Paris: Seuil, 1966.

conferências e intervenções de Lacan feitas por terceiros)

LEMAIRE, Anika. Jacques Lacan; uma introdução. Rio de Janeiro: Campus, 1989.

MELMAN, Charles. Novos estudos sobre a histeria. Porto Alegre: Artes Médicas, 1985.

MACHADO, Arlindo. Psicanálise e cinema. In: CHALHUB, Samira (org.) Psicanálise e o contemporâneo. Sâo Paulo: Hacker, 1996.

ROUDINESCO, Elisabeth. Jacques Lacan, esboço de uma vida, historia de um sístema de pensamento.

São Paulo: Cia das Letras, 1994.

SANTUARIO, Luiz Carlos. Hegel sem Lacan. Conjectura, Caxias do Sul, Educs.

—. Imaginarização do significante e forclusão da culpabilidade. In: STEIN, E. (org.) Veritas, Porto Alegre, Edipucrs.

Educs, 1998.

SAPORITI. Elisabeth. A interpretação. São Paulo: Escuta, 1995.

STEIN, Emildo. Anamnese. Porto Alegre: Edipucrs, 1997.

- Seminário sobre a verdade. Porto Alegre: Vozes, 1993.

TUGENDHAT, Emst. Traditional and analytical philosophy - lectures on the philosophy of language. Cambridge Univ. Press, 1982.

WALDENFELS, Bernhard. De Husserl a Derrida (Introducción a la fenomenología). Barcelona: Paidós. 1997.

${ }^{111}$ SAPORITI. Elisabeth. A interpretação. São Paulo: Escuta, 1995, p. 15. 